\title{
Research on Experience Design of Shu Embroidery Techniques Based on Virtual Reality (VR) Technology
}

\author{
Guilin Zhong ${ }^{1}$, Na Qi ${ }^{1,2 *}$ \\ ${ }^{1}$ School of Art and Design, Xihua University, Chengdu, 610039, China \\ ${ }^{2}$ School of Art, Sichuan Technology and Business University, Chengdu, 620000, China
}

Received 24 September 2020; Revised 03 November 2020; Accepted 17 November 2020; Published 01 December 2020

\begin{abstract}
With the continuous development of digitization, the public's understanding of traditional Shu embroidery techniques is increasingly ignored. Through the combination of VR technology and Shu embroidery techniques, it needs to be deeply excavated and inherited. Based on the inheritance and development of Shu embroidery, literature research, user research, and case studies are used to collect and sort out the current situation of Shu embroidery and its digital inheritance. Around the semiotic characteristics and process flow of Shu embroidery techniques, the interface design and humancomputer interaction experience are studied, and the Shu embroidery skill experience area and game interactive experience area are mainly designed. In conclusion, the innovative inheritance method of Shu embroidery is developed from the transformation of intangible cultural heritage modernization, and VR advanced science and technology is used to provide reference for the design and research of the digital protection platform of Shu embroidery. It is expected that Shu embroidery will be inherited well following the development of the times and then carry forward the traditional technology to the world.
\end{abstract}

Keywords: Digitization; Virtual Reality Technology; Shu Embroidery Techniques; User Experience; Human-Computer Interaction.

\section{Introduction}

Shu embroidery, also known as "Sichuan embroidery", is a precious and unique embroidery process that originated in Bashu. It has a long history and exquisite workmanship. It is an important part of the intangible culture in Bashu. As a unique traditional handicraft, Shu embroidery was listed as the first batch of national intangible cultural heritage in China in 2006. In recent years, the general office of the Chengdu municipal government has further implemented supporting policies and projects to promote the development of the Shu embroidery industry [1-3]. With the development of industrialization, Shu embroidery, as a complicated embroidery technology, has gradually shown a fault trend in the inheritance. Especially under the impact of the material trend of modern civilization, Shu embroidery is more expensive and difficult for ordinary consumers to access. Nowadays, people's understanding of traditional Shu embroidery crafts is increasingly ignored, and facing the shrinkage of culture, how to realize the innovation and inheritance of classics has become an important research problem in the development of Shu embroidery [4, 5]. With the emergence of digital technology, Shu embroidery must broaden its new field of modernization and keep pace with the times with its own advantages. Through the combination of art and technology, it can be deeply excavated, innovated, and applied so as to be better known by the public. Based on the inheritance and development of Shu

\footnotetext{
* Corresponding author: happylife8183@163.com

$>$ This is an open access article under the CC-BY license (https://creativecommons.org/licenses/by/4.0/).

(C) Authors retain all copyrights.
} 
embroidery, this paper analyzes the historical background, technical characteristics, development and inheritance status of Shu embroidery, summarizes the research progress and research results of three kinds of digital inheritance of Shu embroidery through data collection method, literature research method and case analysis method, investigates the application of VR experience of Shu embroidery techniques in combination with user research method, and summarizes the design strategy, Based on the background of digital technology, users experience the exquisite techniques of Shu embroidery through the realization of VR technology, so as to achieve modernization transformation, inherit the traditional process of Shu embroidery, improve the cultural heritage and design charm of Shu embroidery, carry forward the traditional process of Shu embroidery and promote it to the world.

\section{Historical Background and Inheritance Status of Shu Embroidery}

\subsection{Historical Background and Technical Characteristics of Shu Embroidery}

Shu embroidery is one of the four famous embroideries. It has been known as "the treasure of Shu" since ancient times. Its history can be traced back to the Han Dynasty. With the continuous development of economy and culture in the Han, Tang, song and Yuan Dynasties, the development scale of Shu embroidery is also expanding, and gradually reached the peak in the Qing Dynasty. During the Daoguang period of the Qing Dynasty, the Sichuan persuasion bureau began to appear, and embroidery was exclusively for the royal family. After the revolution of 1911, Shu embroidery gradually became popular and has become a daily commodity in our lives. In archaeological data and documents, it is found that the silk reeling and weaving skills of the Shu people existed as early as 4000 years ago, and Chengdu's unique geographical advantages and stable social conditions have enabled the stable development of Shu embroidery. Due to the influence of geographical factors, cultural environment and other aspects, in the long-term continuous development process, it has gradually formed a unique style of preciseness and delicacy, brightness and flatness, bright color and Appropriateness. It mainly takes soft satin and colored silk as raw materials, carries out different color matching according to the embroidery, and uses different stitches to embroider the patterns on silk, silk, yarn, etc.

Due to the variety of patterns of Shu embroidery, which originate from the lifestyle and cultural connotation of Sichuan and Shu people, the theme of patterns also presents diversity. It has experienced a long development stage from abstract patterns to concrete scenery and figures. In the traditional patterns of Shu embroidery, animals [6] and plants [7], cultural relics and buildings [8] are used as pattern materials to convey some morals about receiving auspicious blessings and avoiding evil spirits and disasters. The patterns show people's desire and longing for good things, as shown in Figure 1 and Figure 2:
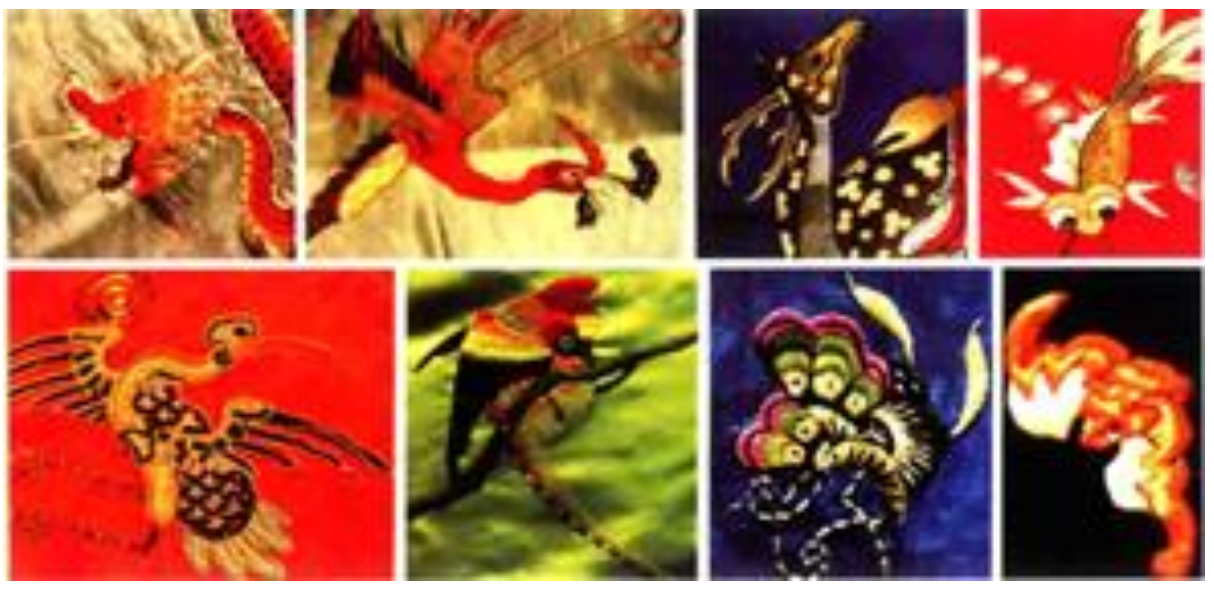

Figure 1. Animal patterns (The picture from Chinese Shu embroidery)
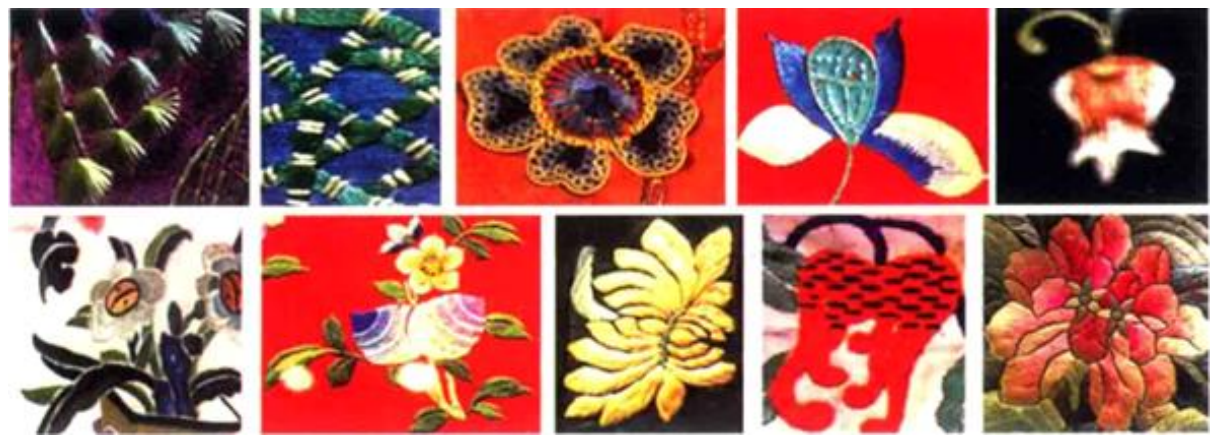

Figure 2. Plant patterns (the picture from Chinese Shu embroidery) 
The design themes of Shu embroidery are mostly flowers and birds, mountains and rivers, insects and fish, figures, etc. specifically, the themes can be divided into animals, geometric patterns, natural environment, plants, buildings, artifacts, characters, character stories and geometric patterns a total of eight categories. Through the implication of panda, carp, animals and other patterns, people express their desire for children the yearning for blessings and exorcising evil spirits and avoiding disasters is shown in Figures 3 and 4:

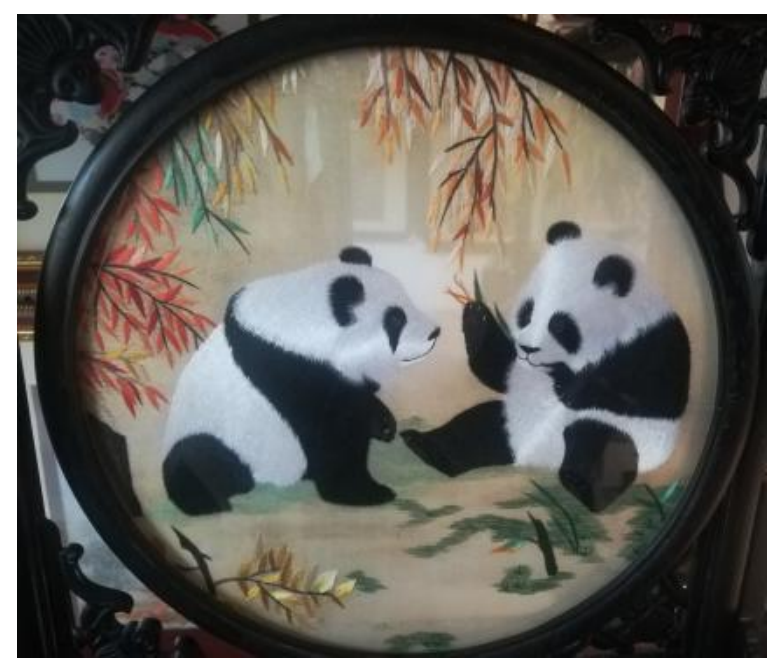

Figure 3. Panda screen

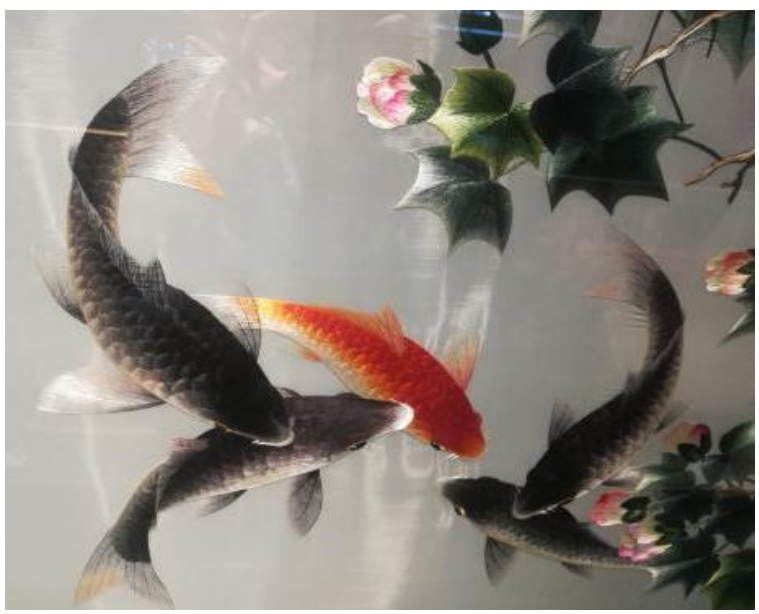

Figure 4. Carp hanging screen

The technical characteristics of Shu embroidery are derived from the rich needlework of Shu embroidery. According to statistics, there are about 130 kinds of needlework of Shu embroidery, which can be divided into 12 categories. Among them, the commonly used needlework includes fainting needle, laying needle, rolling needle, cutting needle, mixing needle, covering needle, etc. the set needle is often used to express the texture of embroidery, reflect the light / color / shape, embroider the embroidery vividly, and cut the silk thread according to different parts of the pattern, Generally, it is cut into $1 / 4$ and 1/2. Different thickness shows different texture. It can be divided into brocade embroidery, double-sided embroidery, flat needle embroidery, random needle embroidery, etc., as shown in Figure 5 below:

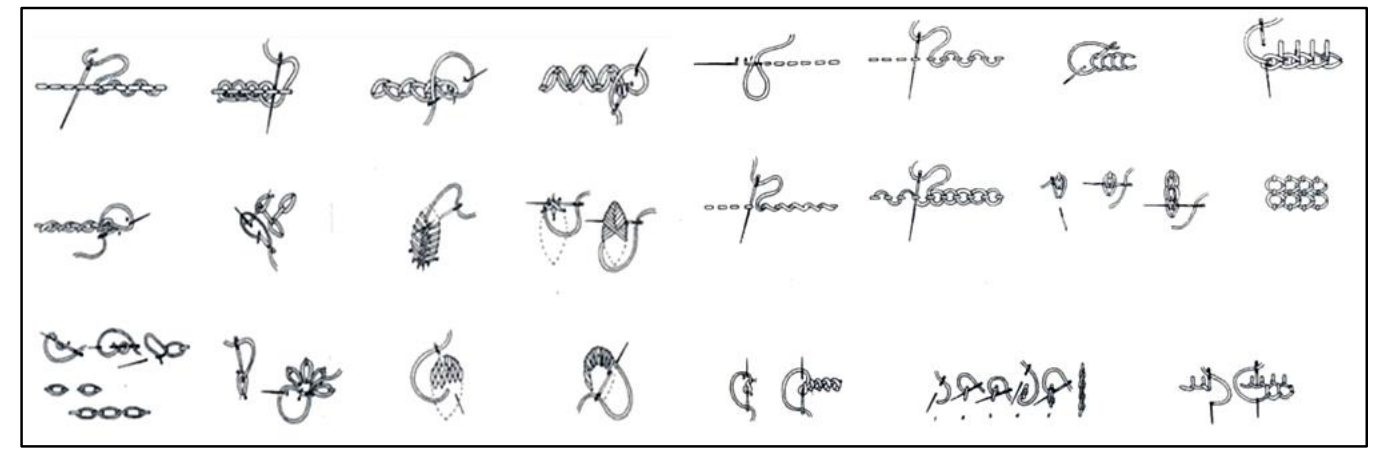

Figure 5. Common needling 


\subsection{Data Availability Statement}

With the continuous development of the information age, the exquisite traditional handicrafts of Shu embroidery have been increasingly ignored by the public, especially young people. All parts of the country have increasingly strengthened their awareness of the importance and urgency of protecting intangible cultural heritage. Through literature research, it is found that there are many literatures on the concept and protection mode of Shu embroidery, but most of them are only analyzed from the theoretical stage, there is a lack of practical research on the combination of protection and development. For example, Zhu (2018) [9] understood the production process, clothing application methods and pattern development process through the field research and investigation of Shu embroidery and Shu Brocade skills, so as to provide new ideas for the innovative design of Shu embroidery skills.

At present, the market of Shu embroidery is chaotic and its development is relatively slow. For example, Ding (2016) [10] made a strategic analysis on the cultural and ecological changes and development of Shu embroidery, and believed that the inheritance and development of Shu embroidery should directly look at the transformation of social form in order to realize the renewal of products and skills. According to the literature research, it is found that there are three main problems: first, it is mostly used as handicrafts and souvenirs, and the products cannot be well integrated with the market, and the content, style and style are relatively single; Second, the process is more complex and time-consuming, which makes Shu embroidery products more expensive, and most people who can afford it are unwilling to understand the development process and embroidery method of Shu embroidery when customizing; Third, the lack of brand awareness, and did not form a well-known brand, unable to give full play to the unique advantages of Shu embroidery. With the emergence of digital technology, Shu embroidery must use its own advantages to broaden its new field of modernization and keeping pace with the times, inherit Shu embroidery techniques, increase people's understanding and meet user experience, so as to create space and bring new opportunities for the rise of Shu embroidery.

\subsection{Current Situation of Digital Inheritance of Shu Embroidery}

With the advent of $5 \mathrm{~g}$ era, there will be a wave of industrialization of digital cultural resources. Digital cultural industry has become the main force to promote the creative transformation and innovative development of intangible cultural resources. With the emergence and development of digital technology, people's traditional ways of learning, living and entertainment have been greatly changed. Through emerging advanced technologies such as Internet, big data and cloud computing, it can provide new opportunities and development trends for inheriting the production process of Shu embroidery. According to the research on the existing digital technology, the current research on the inheritance and protection of Shu embroidery mainly includes the establishment of digital archives and museums. However, there is a lack of systematic scientific research on the protection and innovation of Shu embroidery by using the big data analysis platform. Therefore, there is less relevant literature research. Some scholars mainly focus on the digital filing and classification of Shu embroidery Digital publicity channels, digital long-term preservation standard system and digital long-term protection management mechanism still remain at the theoretical level, and rarely combined with specific practical cases. For example, Jia \& Ruan (2017) [11] studied the app interface design of Shu embroidery culture, promoted the inheritance and development of Shu embroidery culture in a visual way, and established an information platform for benign and common development. Zhu et al. (2009) [12] used jacquard CAD design technology to design Shu brocade products, and applied the design method of hierarchical organization structure to establish holographic Organization database. From the aspect of digital technology, the digital experience of Shu embroidery can be divided into online and offline. Online technical means mainly enable users to use digital museum, mobile app and other methods to match the corresponding design methods to participate in research, design and construction by building a network platform, combined with the traditional process and characteristics of Shu embroidery.

\section{Application of VR Technology in the Inheritance of Shu Embroidery}

\subsection{VR Technology and Inheritance of Intangible Cultural Heritage Shu Embroidery}

Virtual reality technology, abbreviated as "VR technology", refers to promoting users to realize interactive feeling in the virtual world through computer technology, emphasizing immersion and interaction, and creating a humanized multi-dimensional information space. With the continuous maturity and development of VR technology, it is more and more widely used in the inheritance and protection of intangible cultural heritage. Especially in the modern market economy environment, the inheritance of Shu embroidery does not put it on the shelf for future generations, but uses its exquisite skills and profound cultural heritage to attract more people to participate in the inheritance, Therefore, in recent years, a large number of scholars have made relevant research on the application of VR technology in intangible cultural heritage inheritance. Taking the concept of colorful ceramic cultural and creative products as the starting point, Wang (2020) [13] explored the effective inheritance means of traditional patterns in Wuyi overseas Chinese Township under the digital background from three aspects: the digital inheritance strategy of traditional patterns in Wuyi overseas Chinese township. 


\subsection{User Research on VR Experience of Shu Embroidery Techniques}

After extensive collection of literature related to Shu embroidery, through the collation and induction of literature, we conducted on-site investigation and field investigation on Shu embroidery products in Sichuan, visited and interviewed non heritage Shu embroidery culturists and artists, conducted in-depth interviews to understand the views on the digital inheritance of Shu embroidery, combined with VR technology to understand the important achievements and gaps in the current research field, and made a report Through the research of "Shu embroidery technique experience questionnaire", it is found that the current development of Shu embroidery in the market mainly focuses on the development of cultural and creative products related to Shu embroidery, the development of embroidery women, manufacturers and enterprises of Shu embroidery techniques, and the publicity and promotion of museums under the leadership of the government. There are some deficiencies in the development of digital experience. A total of 76 questionnaires were distributed online and on the spot. According to the results of the questionnaire, it was found that in the "18-39 years old" Young people of the age group are most interested in Shu embroidery and VR technology; $63.16 \%$ of users pay more attention to the cultural connotation of Shu embroidery; $65.79 \%$ of users are willing to learn Shu embroidery; while Shu embroidery, $57.89 \%$ of users are willing to understand Shu embroidery techniques; $65.75 \%$ of users are willing to learn Shu embroidery; and $90.79 \%$ of users think it is necessary to set up digital technology in Shu embroidery Museum Experience Shu embroidery. If you can experience embroidery through VR technology and embroider your favorite embroidery, $84.21 \%$ of users are willing to try, as shown in Figure 6 below:

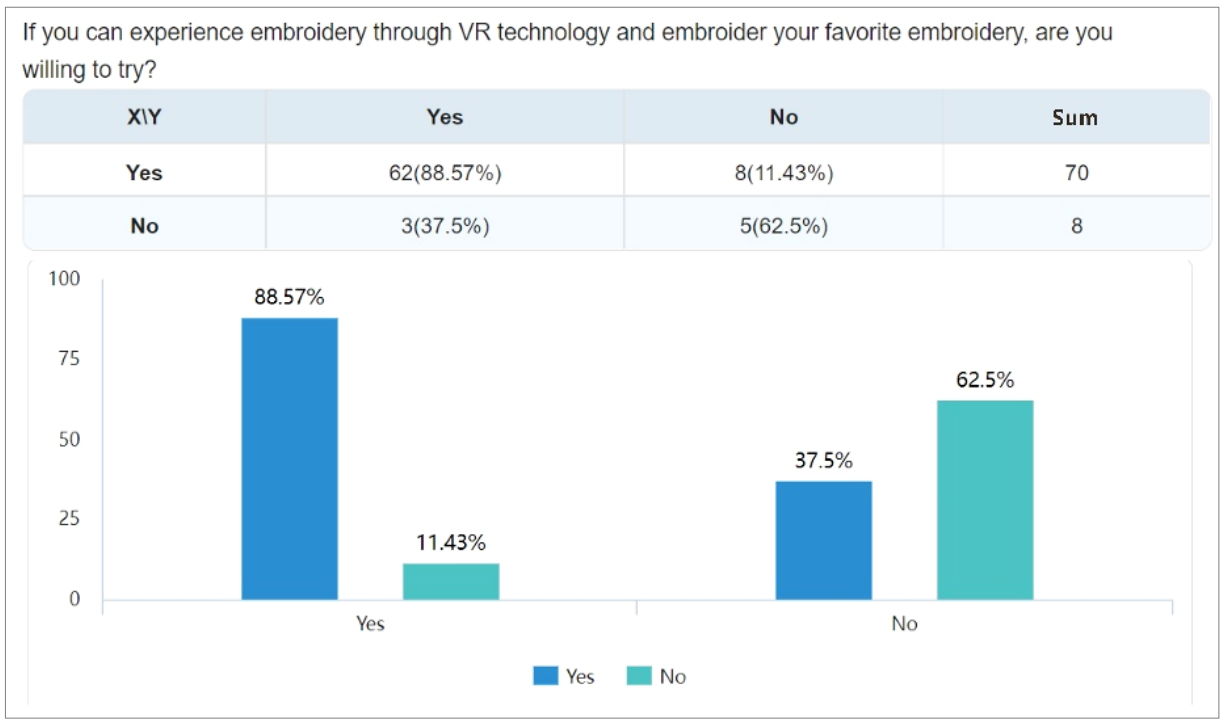

Figure 6. User survey data analysis chart

However, the inheritance of traditional Shu embroidery cannot meet most users' understanding and experience of Shu embroidery techniques, while the digital VR experience can greatly meet the needs of users, especially the tourists who travel to Sichuan, dare to break through and innovate, have a high acceptance of new things, and tend to experience design rich in digital creativity. Therefore, the target user group of Shu embroidery technique experience based on VR technology It is positioned as a youth group. Users can realize human-computer interaction in an allround, multi field and deep level through multimedia booths such as virtual display, interactive participation and skill game experience, so as to enhance the effect of user experience.

\section{VR Experience Design Practice of Shu Embroidery Techniques}

\subsection{Design Principle and Feasibility Analysis}

The design and research of visual modeling and interactive experience through the characteristics, stitching and process flow of Shu embroidery stimulation method should first follow the important principles of scientificity, innovation, importance and verifiability. In terms of design feasibility and technical realization, relying on the Shu embroidery digital museum, it is mainly divided into two design ideas. One is to establish a Shu embroidery skill experience area to show users the process production methods at different stages of Shu embroidery techniques, conduct digital authenticity simulation of Shu embroidery, and combine the science and technology of humancomputer interaction, Create a real three-dimensional visual experience and interactive design from a modern perspective. Users can deeply understand the charm of Shu embroidery in the experience; The second is to establish a game sense interactive multimedia experience area, which can make animated videos digitally and experience VR through the virtual interactive system. The implementation method is scientifically feasible, as shown in Figure 7 below: 


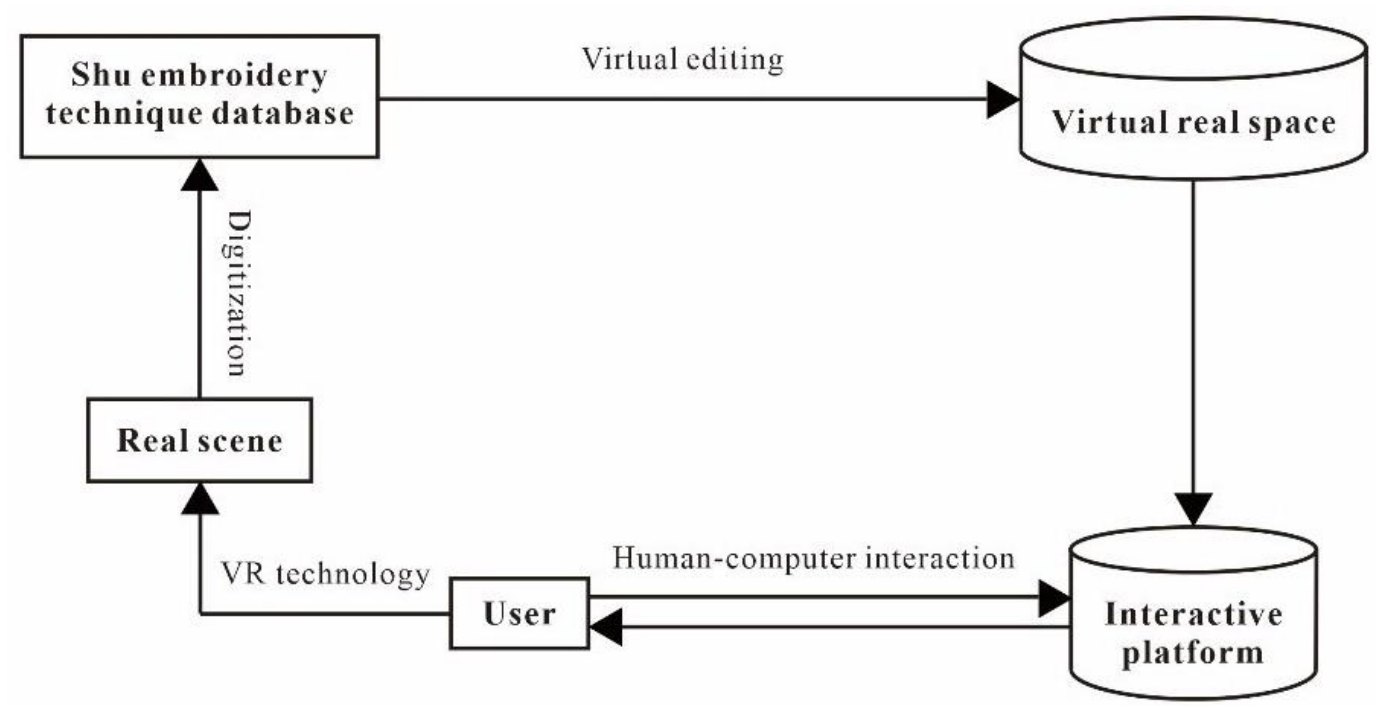

Figure 7. Experience system diagram of Shu embroidery techniques

In the specific area of Shu embroidery digital exhibition hall, users can use the navigation system provided by the three-dimensional virtual platform to roam and browse the history of Shu embroidery, further understand and understand the infinite charm of traditional Shu embroidery techniques by displaying relevant pictures and video materials through trigger operation, and can experience small games related to embroidery and learn the needlework of Shu embroidery Enjoy the animation of Shu embroidery [14]. In the virtual software platform, users can experience the unique artistic charm of Shu embroidery by browsing the excellent works related to Shu embroidery.

\subsection{Design of Shu Embroidery Skill Experience Area}

In the Shu embroidery skill experience area, users manipulate the stitching through the intelligent device interface, so as to embroider their favorite Shu embroidery products on the virtual platform. In terms of implementation, users can operate by themselves. First, design the manuscript, depict the manuscript on the base cloth, and then embroider with needle and thread according to the drawings to complete the final work. The research involved in the experience design of the production process includes the collection of images and data of the production process of Shu embroidery techniques, and the digital production display of techniques and production processes. Users can choose the operation procedures according to their preferences, as shown in Figure 8 below:

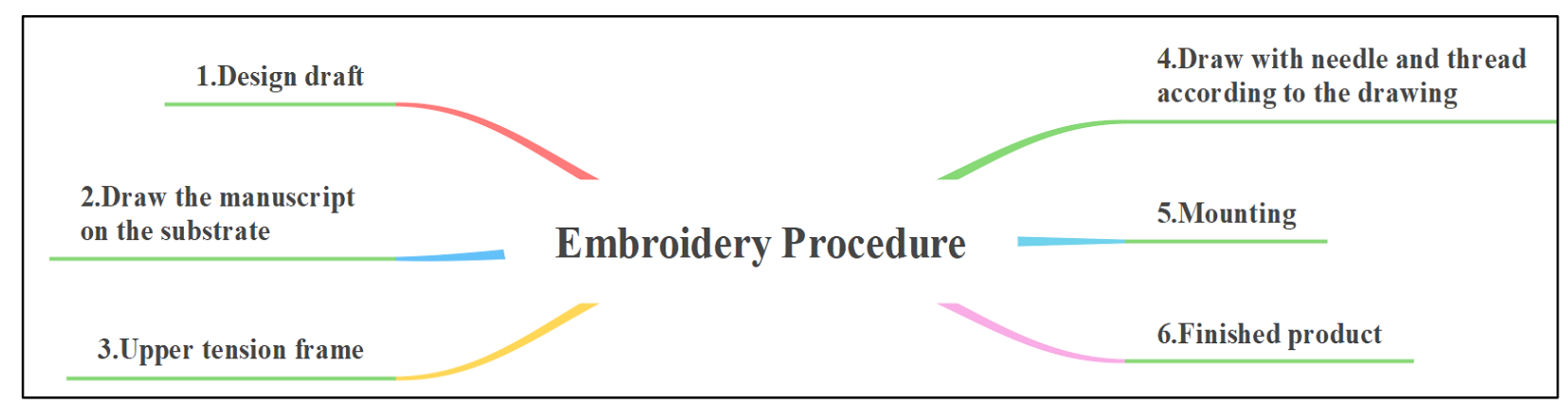

Figure 8. Experience flow chart of Shu embroidery techniques

By experiencing the historical background and development process of Shu embroidery, understanding the production environment of Shu embroidery and allowing users to deeply experience the immersive traditional culture of Shu embroidery, it is conducive to understanding the traditional techniques of Shu embroidery, enhancing users' sense of participation, improving user experience, and being conducive to the good impression and identity of Shu embroidery culture.

\subsection{Design of Interactive Game Experience Area}

Relying on the Shu embroidery digital museum, multimedia interactive experience devices can be placed in specific areas of user experience to experience the multimedia interactive effect of animated game sense. Animation videos can be made digitally. Users can personally participate in the production of Shu embroidery in the video to feel the artistic charm and value of Shu embroidery traditional culture, as shown in Figure 9 below: 


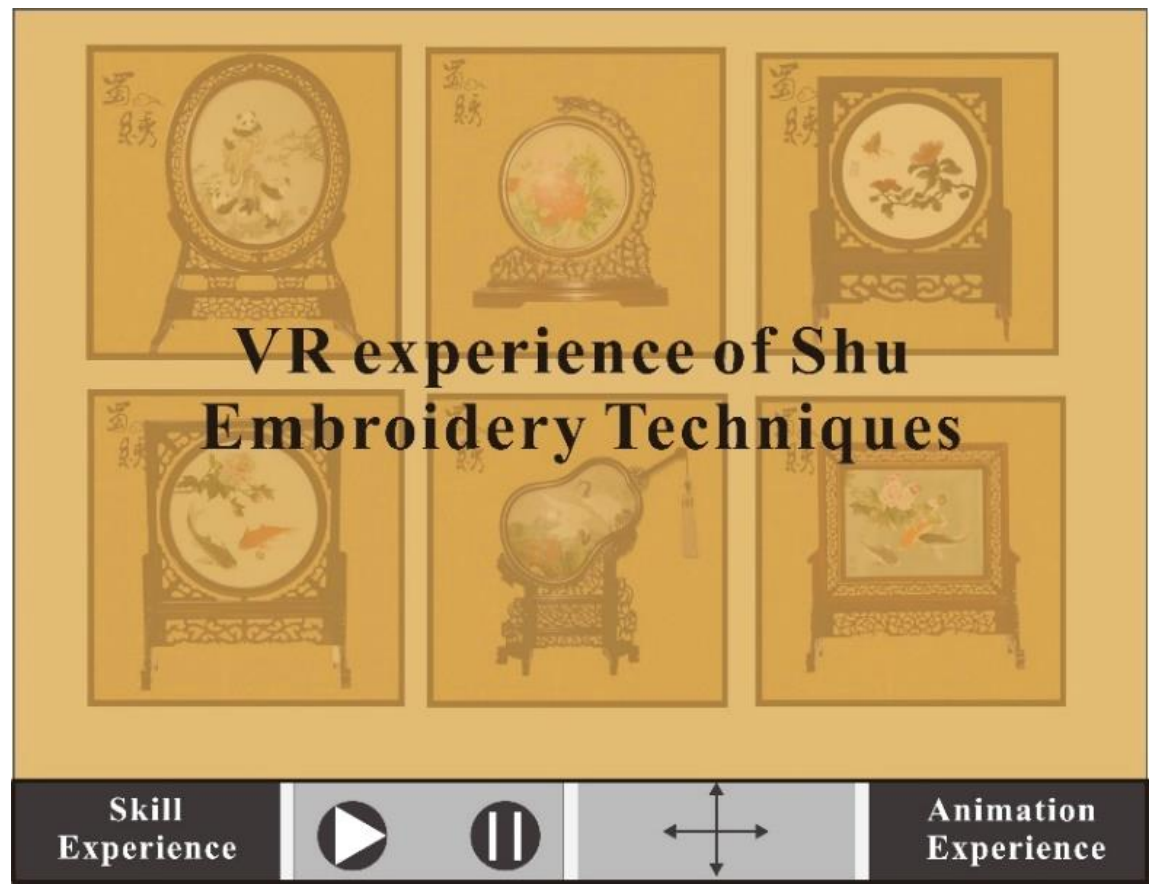

Figure 9. Interface design

Through the animation video interaction of Shu embroidery techniques, considering the purpose of interaction, they put the user experience on the type of Shu embroidery products and the application of Shu embroidery stitches. When users select artistic embroidery through the touch screen, they will immediately list the eight categories of flowers, characters, birds and animals, fish and insects, mountains and rivers, and then the selection of embroidery manuscripts and stitches will appear on the screen. For the selection of embroidery products, users can choose to take art ornaments, sachets, cloth bags, clothes, hats, shoes, and socks, etc. They can learn the unique stitches of Shu embroidery, such as needle rolling, needle fainting, needle laying, and other techniques, and carry out game interaction of Shu embroidery techniques according to their favorite ways to enhance users' sense of pleasure and satisfaction with human-computer interaction.

\section{Conclusion}

With the rapid development of science and technology, virtual reality display technology provides an opportunity for the cultural inheritance and innovative development of Shu embroidery. At the same time, interactive experience design opens up new ideas for the VR design of Shu embroidery techniques. Its value lies in meeting the needs of users to a greater extent and immersing users in the whole scene. It fully demonstrates the pleasure and satisfaction of VR technology in the user experience. The application of digital technology to the inheritance of Shu embroidery techniques is in line with the needs of the development of the information age. This paper explores the digital inheritance mode of the Shu embroidery technique experience. The digital inheritance of Shu embroidery is not only the collection and display of existing achievements but also the follow-up of continuous research. The research results can be used for mining, protection It provides an effective method to spread and carry forward the traditional handicrafts of intangible cultural heritage, Shu embroidery. Through the combination of digital VR technology, the unique technical characteristics of Shu embroidery enable the important inheritance and development of Shu embroidery and realize the modern activation inheritance of no heritage by means of advanced manufacturing technology. Under the background of digital technology, users experience the exquisite techniques of Shu embroidery through the realization of VR technology, so as to achieve modernization transformation, inherit the traditional process of Shu embroidery, carry forward the traditional process of Shu embroidery and promote it to the world.

\section{Declarations}

\subsection{Author Contributions}

Conceptualization, G.Z. and N.Q.; writing — original draft preparation, G.Z. and N.Q.; writing—review and editing, G.Z. and N.Q. All authors have read and agreed to the published version of the manuscript.

\subsection{Data Availability Statement}

The data presented in this study are available on request from the corresponding author. 


\subsection{Funding and Acknowledgements}

The authors acknowledge Research Base of Sichuan Philosophy and Social Science "Modern Design and Culture Research Center" (Grant No. MD21E018), Key research base of Humanities and Social Sciences in Sichuan Universities "Rural Early Childhood Education Research Center" (Grant No. NYJ20190605), Research Base of Sichuan Philosophy and Social Science "Sichuan old revolutionary base area development research center" (Grant No. SLQ2017B-10) and Talent Introduction Project of Xihua University (Grant No. Z202110).

\subsection{Institutional Review Board Statement}

Not applicable.

\subsection{Informed Consent Statement}

Not applicable.

\subsection{Declaration of Competing Interest}

The authors declares that there is no conflict of interests regarding the publication of this manuscript. In addition, the ethical issues, including plagiarism, informed consent, misconduct, data fabrication and/or falsification, double publication and/or submission, and redundancies have been completely observed by the authors.

\section{References}

[1] Shadiev, R., Wang, X., \& Huang, Y. M. (2020). Promoting Intercultural Competence in a Learning Activity Supported by Virtual Reality Technology. The International Review of Research in Open and Distributed Learning, 21(3). doi:10.19173/irrodl.v21i3.4752.

[2] Wang, J., Chen, Y. W., Zhong, H., \& Wang, A. (2020). Human-computer Interactive Showcases Design for the Application of Commercial Space. 2020 International Conference on Innovation Design and Digital Technology (ICIDDT). doi:10.1109/iciddt52279.2020.00017.

[3] Xinyong, Y., \& Yanli, D. (2020, August). Research on the Application of Digital Virtual Technology in the Protection and Innovation of Intangible Cultural Heritage in China-Three Types of Carvings in Huizhou as an Example. In 2020 4th International Seminar on Education, Management and Social Sciences (ISEMSS 2020), 247-252. Atlantis Press.

[4] Yang, Y., Shafi, M., Song, X., \& Yang, R. (2018). Preservation of Cultural Heritage Embodied in Traditional Crafts in the Developing Countries. A Case Study of Pakistani Handicraft Industry. Sustainability, 10(5), 1336. doi:10.3390/su10051336.

[5] Li, M., \& Zhang, X. (2017). Research on the Application of Traditional Embroidery Technology in Modern Jewelry Creation. Journal of Arts and Humanities, 6(10), 07. doi:10.18533/journal.v6i10.1274.

[6] Kuang, Y., \& Cui, R. (2015). Patterns on the Embroidered Textiles Unearthed from the Silk Road I: Animal Pattern. Asian Social Science, 11(27), 246. doi:10.5539/ass.v11n27p246.

[7] Tamburini, D., Cartwright, C. R., Pullan, M., \& Vickers, H. (2018). An investigation of the dye palette in Chinese silk embroidery from Dunhuang (Tang dynasty). Archaeological and Anthropological Sciences, 11(4), 1221-1239. doi:10.1007/s12520-017-0592-4.

[8] Lau, T. (2011). The Grading of Cultural Relics in Chinese Law. International Journal of Cultural Property, 18(1), 1-35. doi:10.1017/s0940739111000075.

[9] Zhu R. (2018). Investigation and innovative application of Shu embroidery and brocade. Western leather. doi:10.3969/j.issn.1671-1602.2018.14.087.

[10] Ding, M. (2016). Ecological changes and development strategies of Shu embroidery culture. Beauty and the times (Part I). doi:10.3969/j.issn.1003-2592(s).2016.03.009.

[11] Jia, Y., Ruan C. (2017). Research on app interface design of Shu embroidery skill inheritance in the new media era. Digital design, 11, 78-94. doi:10.19551/j.cnki.issn1672-9129.2017.09.019.

[12] Zhu L., Zhang X., Liao X. (2009). Design of new Shu brocade products using jacquard weaving CAD. China Textile Leader, 2009(11), 104-105. doi:10.3969/j.issn.1003-3025.2009.11.036.

[13] Wang J. (2020). Research on digital inheritance of traditional patterns in Wuyi overseas Chinese Township. Industrial design, 3(1), 256-263. doi:10.3969/j.issn.1672-7053.2020.03.073.

[14] Cui, L., \& Shao, X. (2020). Intelligent Media Technology Empowered Brand Communication of Chinese Intangible Cultural Heritage. In International Conference on Machine Learning and Big Data Analytics for IoT Security and Privacy, 115-121. Springer, Cham, Switzerland. doi:10.1007/978-3-030-62746-1_17. 